\title{
Prostituição Infantil: Uma Questão de Saúde Pública
}

\section{Child Prostitution: A Public Health Issue}

\section{Romeu Gomes ${ }^{1}$}

GOMES, R. Child Prostitution: A Public Health Issue. Cad. Saúde Públ., Rio de Janeiro, 10 (1): 58-66, Jan/Mar, 1994.

This article analyzes child prostitution based on a review of the literature, in order to support an approach to this problem by the field of Public Health. First, health, prostitution, and violence are discussed as categories. Prostitution has traditionally been analyzed from a medical perspective, mostly within a hygienist point of view. However, the issue is dealt with here from a different perspective. After this discussion, several aspects about the cruelty of Brazilian reality are reveled showing that prostitution among children and teenagers is a way of survival. From this angle, poverty and child prostitution are closely related, although the study concludes that the latter is not solely a consequence of the former. Over the course of the review, a number of publications on the current issue are taken into consideration in order to best contribute to the discussion of the matter. Finally, the author concludes that to confront this problem it must be considered within the family context and linked to macro-social questions.

Key words: Prostitution; Child Abuse, Sexual: Violence; Public Health

\section{INTRODUÇÃO}

A prostituição tradicionalmente já constitui objeto da Saúde Pública, principalmente inserida dentro de uma ótica higienista. Se esta temática já é um objeto consagrado nessa área, por que se propor a inclusão da prostituição infantil como questão de saúde pública? Será que está se propondo a reedição de uma velha questão?

$\mathrm{Na}$ tentativa de responder a essas indagações, podem ser ressaltadas considerações fundamentais sobre o assunto. Quando se fala de prostituição infantil, aponta-se para uma realidade distinta da prostituição em geral, configurando-se outro conjunto de determinações. Por outro lado, a abordagem que se pretende propor não se reduz à concepção higienista. Assim, pretende-se colocar na agenda da Saúde Pública uma nova questão.

Aceito este argumento, logo se faz necessário precisar de qual saúde pública está se falando.

\footnotetext{
${ }^{1}$ Faculdade de Educação da Universidade do Estado do Rio de Janeiro. Av. São Francisco Xavier, 524, $12^{\circ}$ andar, Rio de Janeiro, RJ, 20559-900, Brasil.
}

Conforme Frenk (1992) assinala, na saúde confluem diferentes dimensões e aspectos. Numa dimensão há as instâncias do biológico e do social; em outra há o indivíduo e a comunidade; e ainda em outra há a política social e a política econômica. Partindo-se do pressuposto de que a saúde é um meio de realização pessoal e coletiva, a Saúde Pública deve levar em conta esses diferentes prismas relacionados ao seu objeto.

Para este autor, recentemente tem se discutido a idéia de que a qualidade "pública" da expressão Saúde Pública refere-se a uma dimensão de análise que consiste no nível populacional. Neste sentido, "público" não é um conjunto de serviços em particular, nem uma forma de propriedade, nem ainda um tipo de problema.

A Saúde Pública, devido à sua natureza, volta-se para uma perspectiva baseada em grupos ou populações. Esta perspectiva inspira sua aplicação, seu conhecimento e seu âmbito de atuação. A partir do princípio multidisciplinar de investigação, pode-se, assim, definir Saúde Pública como aplicação das ciências biológicas, sociais e da conduta ao estudo do fenômeno saúde em populações humanas.

Nesta perspectiva, o processo saúde-doença 
como observam Birman (1991), Minayo (1991) e Ruffino-Neto (1992), traduz-se pela inter-relação entre aspectos de ordem clínica e sociológica. Assim, faz-se necessário levar em conta além dos aspectos anatômicos e fisiológicos valores, atitudes e crenças que se encontram no universo das representações dos atores sociais que vivenciam este processo.

Nunes (1988) - ao analisar a trajetória da Medicina Social brasileira, recentemente denominada Saúde Coletiva, iniciada no século XIX - assinala a progressiva incorporação, por parte da saúde, do caráter político que lhe é inerente e da dimensão social como objeto privilegiado do saber na compreensão do coletivo. Este autor, com base em Laurell, observa que cada vez mais vem se concebendo saúdedoença como um processo de caráter social em si mesmo e não apenas socialmente determinado.

Retomando as idéias de Frenk (1992), para se chegar a uma nova Saúde Pública é preciso que haja um esforço interdisciplinar que tem como conseqüência uma abertura conceitual. É dentro desta abordagem que se inscreve a questão aqui proposta.

Após essa discussão conceitual, outra deve ser estabelecida no que diz respeito à prostituição em geral. Para Scambler et al. (1990), por exemplo, esta denominação é empregada como um trabalho igual a outro qualquer, definindo a prostituição como uma forma de trabalho sexual, enquanto uma transação de negócios: tem de haver um comprador e um vendedor, comodidade oferecida e preço fixado. Nesta transação, troca-se gratificação sexual por uma taxa estabelecida, não havendo nenhuma pretensão à afeição.

Essa concepção difere do posicionamento de Barry (1991), que concebe a violência sexual e a prostituição como violações da dignidade humana, crimes contra a mulher e formas de discriminação sexual. No Terceiro Mundo, segundo a autora citada, a prostituição, associada à vulnerabilidade econômica, assume configurações brutais.

$\mathrm{O}$ argumento de que a prostituição é uma forma de trabalho é atacado por Barry (1991). Comparando o trabalho de jogadores de beisebol com a prostituição, a autora verifica que o jogador, embora contratado para usar o seu corpo nunca entrega seu corpo, nem seus atributos para quem o contrata. $\mathrm{Na}$ prostituição, ao contrário, obtêm-se o direito unilateral ao uso sexual direto do corpo por parte do comprador.

Encarar a prostituição como questão de uma cultura específica é uma atitude também a ser combatida. Segundo o ponto de vista da autora citada, o ato da prostituição é essencialmente o mesmo em diferentes culturas, com variações produzidas por demandas racistas de clientes.

Por último, Barry (1991) observa que quando se situa a prostituição como uma violação dos direitos humanos e como um crime contra a mulher, podem surgir objeções de que isso afetaria as mulheres que optam por ser prostitutas, mesmo tendo outras alternativas, e criminalizar seus clientes seria injusto. Rebatendo este argumento, a autora afirma: "na África do Sul há negros que participam do apartheid, contribuem e ganham com o apartheid. Mas isso não justifica o apartheid".

A ida de mulheres para a prostituição é fortemente influenciada pela ideologia machista reinante. Para Saffioti (1989), a moça - quando vítima de violência sexual, que vai da sedução ao estupro - pode se ver como indigna de viver em sociedade, onde só há lugar para as virgens e casadas. Não se enquadrando em nenhuma dessas situações, ela encontra a zona de prostituição como solução. Por outro lado, para que na sociedade haja "gente de família", a prostituição passa a ser o perfeito mal necessário, uma vez que se concilia o incentivado treinamento sexual masculino pré-matrimonial com o fato de a moça chegar virgem ao casamento.

Ao se abordar a prostituição, independente do tipo de enfoque, não se pode deixar de lado a idéias de que esta temática insere-se na categoria do estigma. Em Goffman (1988) pode-se encontrar base para uma melhor compreensão desta categoria. Segundo este autor, as atitudes das pessoas tidas como "normais" em relação às pessoas com um estigma possuem características peculiares. Em geral, essas atitudes são perpassadas por vários tipos de discriminação. Elas fundamentam-se, comumente, numa teoria de estigma e numa ideologia que serve para racionalizar, entre outros, dois aspectos 
centrais: a inferioridade de quem é estigmatizado e o perigo que essa pessoa representa.

Essas atitudes presentes na sociedade devem ser levadas em conta para se compreender aspectos interiores da prostituição e suas relações com a vida social em geral. Não considerar isso significa, no mínimo, reforçar o preconceito que impede um melhor entendimento da temática em questão.

A partir da articulação entre a Saúde Pública, enquanto campo de conhecimento e práticas multidisciplinares, e prostituição, enquanto violação dos direitos humanos, é que se afigura o presente artigo.

\section{PROSTITUIÇÃO E SABER MÉDICO: ASPECTOS HISTÓRICOS}

Sem a pretensão de se fazer um quadro cronológico sobre o saber médico relacionado à prostituição, pode-se destacar aspectos do passado que, ao serem perfilados, podem ajudar na compreensão de como tradicionalmente constitui-se este saber. Entre os estudos que contribuem para esta compreensão destacam-se os de Machado et al. (1978), Engel (1986, 1989) e Soares (1986). Esses trabalhos, no que diz respeito ao saber médico sobre a prostituição, são baseados em documentos, em geral teses de medicina, do século XIX, produzidos na cidade do Rio de janeiro. As análises que realizam possuem aspectos comuns e pontos distintos sobre o assunto.

Machado et al. (1978) apontam para o fato de o saber médico da época revelar a prostituição como um perigo físico e moral. Por outro lado, este objeto do saber médico também era visto, ao mesmo tempo, como um fato natural e social.

Enquanto perigo físico, segundo esses autores, a prostituição era identificada como causa de doença; no caso, havia principal destaque para a sífilis. Do leito da prostituta para o leito da esposa, o homem poderia passar o mal que deforma e mata, que se estende para os seus descendentes. Além da sífilis, inúmeras e variadas doenças são apontadas pelos médicos da época como conseqüências da cópula desenfreada e desregrada. Insônia, ansiedade, ardor de entranhas, decadência progressiva de forças, poluções noturnas e sintomas nervosos são exemplos que figuram na lista dessas doenças.

A dimensão física presente no discurso médico da época, segundo análises de Engel (1986), inseria a prostituição no espaço da sexualidade pervertida, em contraposição ao casamento, visto como espaço da sexualidade sadia. As imagens do cancro e da úlcera são exemplos dos diagnósticos presentes neste discurso, apontando para a idéia de ser a prostituição uma enfermidade ameaçadora da saúde e da vida. Este enfoque denota uma certa preocupação com o corpo enquanto aspecto físico. Assim, o corpo da prostituta em si é visto como "uma doença do corpo que corrói o próprio corpo (...) E que ameaça outros corpos" (Engel, 1986).

Junto às doenças físicas, os médicos advertiam sobre as consequiências morais advindas da prostituição. Essa prática poderia ser um exemplo pernicioso para as moças: desestimular o trabalho e estimular o vício, entre outros problemas morais. "A prostituição desenfreada e 'Iivre' é colocada como obstáculo à transformação da família em um local de produção de indivíduos saudáveis" (Machado et al., 1978).

Como observa Engel (1986), o papel da prostituta - visto como oposto ao da esposa relacionava-se ao exercício da paixão - oposto ao exercício do amor. Este papel, para os médicos da época, vinculava-se ao adultério e à degradação dos costumes, representando o espaço da sexualidade moralmente doente, e, assim como a doença física, essa sexualidade doente também possui um caráter contagioso que ameaça os costumes.

Por outro prisma de análise, para Machado et al. (1978), os médicos viam a prática da prostituição como, simultaneamente, um fato natural e social. Esta prática, presente em todos os países e nas eras mais primitivas, segundo o saber médico da época, estava ligada ao organismo humano, permitindo que o instinto sexual se realizasse e promovendo uma entrega ao desejo arrebatador. Neste sentido, para este saber, era na própria natureza humana que dever-se-ia estudar a patogenia da prostituição.

Por outro lado, a dimensão social da prostituição também é ressaltada nos documentos médicos do século passado. Entre as causas desta prática, enquanto fato social, destaca-se o 
excesso de riqueza e a miséria, que se explicam pela organização da sociedade. Neste quadro, uns a procuram e outros a ela se entregam como forma de sobrevivência, onde são articulados diferentes gradientes da miséria do povo e das paixões dos ricos, conforme assinalam Machado et al. (1978).

Vinculada à ociosidade - em oposição ao trabalho - a prostituição situava-se no campo das atividades remuneradas ilegítimas. Junto à essa idéia, na visão de Engel (1986), o discurso médico da época revela preconceitos sobre o trabalho feminino, quando concebe costureiras, floristas e enfermeiras, entre outras trabalhadoras femininas, como prostitutas enrustidas. Sob o ponto de vista deste saber médico, a prostituição - produto da indolência, da ambição e da miséria - é fruto da doença social em dois sentidos: "seja enquanto espaço de reprodução da miséria, seja enquanto lugar de produção do luxo ilícito" (Engel, 1986). Essa doença social ameaçaria a própria riqueza da nação, por ser foco de desagregação do trabalho e da propriedade.

Engel, em outro texto (1989), destaca que o saber médico da época (1845-1890) oscilava entre o caráter normativo e a extinção da prostituição. A primeira vertente deste saber voltava-se mais para o controle médico, enquanto a segunda era pontuada pelo repressão policial. Seja sob a ótica da higiene, seja pela visão moralista dos abolicionistas, a prostituição foi incorporada à reflexão médica como uma doença que ameaçava a população e que, como tal, deveria ser controlada ou combatida.

"Para conhecer a prostituição foi preciso deixar de vê-la apenas como pecado, para convertê-la, antes de tudo, em doenças" (Engel, 1989). O discurso médico fixou os limites entre a moralidade e a doença no campo da sexualidade, trazendo implícito um projeto de criar normas higiênicas do corpo, que era concebido não apenas num sentido físico, mas também num sentido moral e social. A partir desta perspectiva, o médico construía as categorias básicas de classificação: a perversão (a doença física), a depravação (a doença moral) e o comércio do corpo (a doença social).

Como não podiam acabar com a prostituição, conforme analisa Soares (1986), já que era considerada um "grande mal", mas um "mal necessário", para a estabilidade da família e de toda a sociedade, médicos e autoridades policiais lançaram-se à sua regulamentação. No entanto, para esses mesmos médicos e autoridades, se a prostituição pública tinha de ser tolerada, a prostituição clandestina, ao contrário, deveria ser combatida, uma vez que esta escapava à vigilância. Neste cenário do século passado surge a proposta da criação do bordel higienizado, com vantagens para a sociedade. Esta proposta, no entanto, praticamente não foi concretizada, uma vez que a mesma necessitava de uma política - para regulamentar e normatizar o meretrício - que não chegou a ser implantada.

Soares (1986), com base em Machado et al. (1978), assinala que a comunidade médica, ao propor o controle da prostituição, não estava na verdade negando ou reprimindo o sexo, mas sobretudo desejava conhecer todas as suas dimensões.

Este saber do século XIX, para Nunes (1988), inseria-se na "tematização da saúde no espaço urbano". Neste sentido, segundo o referido autor, a análise dos espaços que representavam perigo de doença e de desordem, como o bordel, completava o conhecimento sobre a cidade e o esquadrinhamento urbano. No final do século XIX, ainda no entendimento de Nunes (1988), emerge o movimento sanitarista, juntamente com a posição que situa a saúde como uma questão social. Essa realidade vai permanecer até as primeiras décadas do século XX.

No âmbito do saber médico que atravessa o fim do século XIX até o início do presente século, a prostituição associou-se às doenças venéreas, a ponto de, segundo Carrara (s/d), não se poder fazer uma história dessas doenças sem se falar da prostituição. Nesta associação perpassa a difícil questão de se atuar frente ao estigma. Para este autor, assim como atualmente vincula-se a AIDS aos homossexuais masculinos, no passado, a sífilis era vinculada à figura da prostituição.

Junto à idéia de que a prostituição é uma doença, atualmente percebem-se outros enfoques sobre o assunto. Vislumbra-se, por exemplo, um enfoque que se desloca da idéia de "grupos de risco" para a de "práticas de risco". 
Este posicionamento que surge na era da AIDS, dentro de uma perspectiva de saúde coletiva, orienta-se para uma nova concentração de doença. Nesta concepção, o foco de atenção não está sobre alguns indivíduos, segregando-os, mas na sociedade como um todo. "Mesmo que haja indivíduos ou grupos mais expostos, é toda a sociedade que está imediatamente implicada no processo"(Carrara, s/d).

\section{PROSTITUIÇÃO INFANTIL: ESPAÇO DE VIOLÊNCIAS}

As estimativas que se tem sobre prostituição infantil no Brasil revelam um quadro sério e preocupante. Saffioti (1989) cita a estimativa do Fundo das Nações Unidas para a Infância (Unicef), que levanta a possibilidade de $20 \%$ das meninas brasileiras entre 10 e 15 anos exerceram a prática da prostituição. Em Dimenstein (1992) há outra estimativa, do Centro Brasileiro para a Infância e Adolescência (CBIA), que aponta para a existência de 500 mil meninas brasileiras que vivem na prostituição. Um levantamento local, mencionado por Vasconcelos (1991), aponta para o fato de, num espaço de 40 dias, ter havido mais de 1.000 meninas e adolescentes do sexo feminino que buscavam sobrevivência nas ruas e nos bordéis do Recife.

A prostituição infantil, em qualquer cenário em que se configura, desponta como um fato cruel com diferentes matizes. Há momentos em que ela se integra ao tráfico de drogas; há situações em que ela se confunde com a miséria; e há casos em que seu início ocorre dentro do próprio lar. Em qualquer uma dessas situações, as crianças que a ela sobrevivem têm uma história comum a contar: a história da violência. As marcas desta violência são visíveis nos corpos e nas mentes, mesmo para aqueles que fazem força para não ver.

Segundo Luppi (1987), a prostituição infantil é um dos problemas mais cruéis e comuns a que está exposta a infância pobre do Brasil. Para o autor, paradoxalmente, esta temática é uma das menos pesquisadas dentro do conjunto de estudos sobre a chamada "questão do menor". A precariedade de dados sobre este assunto também é apontada por Saffioti (1989) e Lamarão et al. (1990).
No levantamento preliminar acerca da problemática em questão, em termos de estudos brasileiros que envolvem trabalho de campo, ressaltam-se apenas quatro investigações. $\mathrm{O}$ primeiro estudo, citado por Vasconcelos (1991), aborda a realidade de meninas que vivem nas ruas do Recife (Pernambuco), e dentro desta análise há uma reflexão sobre a venda do corpo como forma de sobrevivência, por parte das meninas. No segundo, de Santos et al. (1990), além de considerações teóricas sobre a temática em questão, há uma breve análise comparativa sobre a prostituição infantil, a partir de dados presentes em entrevistas com educadores que trabalham diretamente com meninas de Fortaleza (Ceará). No terceiro, realizado por Lamarão et al. (1990), são examinadas causas e formas de exploração sexual de meninas de Belém (Pará), a qual encontra-se relacionada à pobreza. Por último, o quarto estudo é um trabalho de jornalismo-pesquisa, de autoria de Dimenstein (1992), que revela, com todos os seus impactos, a perversidade do tráfico de meninas escravas na Amazônia legal.

Para Saffioti (1989), praticamente há uma sobreposição da prostituição e da pornografia infantis. No cenário internacional, o uso de crianças na grande indústria pornográfica já é um fato alarmante. Em Lorenzi (1987) há um dado que registra, nos Estados Unidos, para o ano de 1987, a existência de 250 publicações especializadas nessa área, envolvendo crianças de 3 a 5 anos. No Brasil, como observa Saffioti (1989) não se dispões de cifras sobre a pornografia infantil.

O uso da droga e a prostituição infantil são associados por alguns autores. Este uso é mencionado por Vasconcelos (1991) como uma das formas de as meninas "agüentarem a vida de rua”. Já Dimenstein (1992) observa que a rede de prostituição se cruza e se confunde com a rede do tráfico de drogas.

Quando se fala em prostituição infantil, pensa-se na prostituição infantil feminina. Entretanto, há também a masculina, mas sobre esta praticamente nada se sabe. As obras levantadas sobre a temática do presente artigo praticamente não apresentam dados sobre esta realidade. Alguns autores apenas a constatam e observam a ausência de dados sobre a prostituição infantil masculina. 
Especialmente sobre a prostituição infantil feminina, Saffioti (1989), em termos conceituais, observa que há duas abordagens sobre exploração sexual: uma se confunde com o conceito de exploração econômica, enquanto outra se refere à obtenção de prazer, com prejuízos da saúde mental de quem está sendo explorado. Nas duas abordagens está implícita a idéia de dominação, perpassada pelas categorias de sexo e idade. Isso é melhor explicado a partir do fato de a sociedade ocidental ser "androcêntrica" e "adultocêntrica", nela se tornando visíveis o poder do homem e o poder do adulto. Esta dupla opressão da qual a menina-prostituta é vítima também encontra-se assinalada em outros autores, como Santos (1991).

Desdobrando mais este posicionamento, Saffioti (1989) estabelece duas considerações básicas. A primeira refere-se ao fato de a educação promovida pelo adulto ser fortemente comprometida por uma visão machista. $\mathrm{Na}$ segunda consideração está presente a idéia de que, no âmbito social, o poder associa-se à violência. Na medida em que o homem detém maior poder, lhe é permitido desenvolver a violência. Em geral, segundo a autora em questão, a violência sexual desenvolve-se a partir da dominação do macho.

A violência contra crianças em geral deixa marcas profundas nas suas vítimas. Vasconcelos (1991) relata que, na Casa da Passagem, no Recife, no período de 1987 a 1989, 3.700 questionários registram violências praticadas contra meninas e mulheres-adolescentes, destacando-se estupros, incestos, espancamentos e abusos sexuais. As consequiências da violência sexual são analisadas por Santos (1991) e Vittielo (1989). Especialmente em relação à menina que se prostitui para sobreviver, observa-se que o seu corpo, cobiçado e violentado, se converte em "objeto privilegiado das agressões por parte dos outros; seja comprando-o, seja maltratando-o"(CEAP, 1993).

Num primeiro plano, comumente pode-se ver a violência sexual como protagonista principal. No entanto, ao se descortinar este plano, logo se percebe, em quase a totalidade dos casos de prostituição infantil, fortes indícios de violência estrutural. Este nível de violência é forjado por um sistema social desigual, onde um enorme número de pessoas é explorado para garantir privilégios de um pequeno número de outras.

Em relação à violência, observa-se que, no âmbito do senso comum, esta comumente é vista somente num plano individual. No entanto, há inúmeras análises, a exemplo das de Vethencourt (1990) e Vásquez (1990), que ressaltam a sua dimensão social.

Os diferentes níveis da violência são sistematizados e analisados por Minayo (1990) de forma bem clara. O primeiro nível - a violência estrutural - caracteriza-se pela existência de um sistema social desigual, tendo como consequiência a fome, o desemprego e os demais problemas sociais enfrentados pela classe trabalhadora. Já o segundo nível - a violência revolucionária - relaciona-se à resistência, que se expressa na luta de grupos oprimidos e discriminados contra a dominação legitimada. Por último, o terceiro nível - a delinqüência diz respeito às chamadas transgressões sociais, que não podem ser entendidas, de forma simplista, como um fenômeno natural, uma conduta individual patológica ou um atributo de pobres e negros. A autora citada observa que qualquer forma de violência não pode ser compreendida isoladamente, e sim vista em rede.

A violência que permeia a prostituição infantil feminina por si só já constitui uma questão de saúde coletiva. Esta afirmação se insere numa constatação mais ampla, objeto de análise de Goldenberg et al. (1989), que ressaltam a violência contra a mulher na sociedade brasileira. Esta violência estrutura-se a partir da organização hierárquica das relações de gênero, potencializada por atos violentos, revelando o papel subalterno das mulheres presente no imaginário social. Segundo Goldenberg et al., a saúde coletiva deve enfrentar esta questão, que, além das marcas psíquicas produzidas, ameaça a integridade física da mulher. A saúde da mulher, como observam Xavier et al. (1989), não se restringe à condição corporal, mas estende-se para outros campos. Entre esses campos podem ser destacadas a sexualidade e a violência. Além dos autores citados, há outros, como Agudelo (1989) e Minayo (1992), que vêm discutindo a violência como uma demanda em saúde.

Quase todos os autores tecem considerações 
sobre a miséria presente por detrás da prostituição infantil, sem reduzir a segunda à primeira. Azevedo (1986), por exemplo, além das condições sócio-econômicas, analisa outros fatores, como o desenvolvimento do turismo e a "ideologização" da infância e das sexualidades feminina e masculina. Segundo a autora, esta ideologização faz com que, entre outras coisas, haja uma divinização da ninfeta.

Sem dúvida, a miséria tem uma pontuação maior entre os inúmeros fatores mencionados pelos autores. Sobre isso, Santos et al. (1990) observam que, em geral, a trajetória da menina de rua inicia-se na mendicância, passa pelas pequenas vendas nos sinais e tem como fim a prostituição.

Para Saffioti (1989), as profundas desigualdades sócio-econômicas do país propiciam a exploração de pessoas por pessoas. Neste contexto, a criança facilmente se torna uma mercadoria. Segundo a autora citada, esta problemática deve ser entendida nos níveis nacional e internacional.

Em Dimenstein (1992) também fica patente a presença da miséria no cenário da prostituição de meninas escravas no Brasil. Entre suas conclusões sobre esta perversa realidade, o autor ressalta o fato de a miséria fazer com que as meninas vendam o único bem que possuem: o corpo. Outra conclusão do autor sobre o tráfico de meninas escravas, ligado ao tráfico de drogas, diz respeito à idade de ingresso na prostituição, que diminui à medida que aumenta o número de crianças que vivem na rua.

Uma das conseqüências deste quadro nacional de pobreza é, sem dúvida, o chamado fenômeno de "meninos e meninas de rua". Minayo et al. (1992) consideram que esta problemática afigura-se como um fenômeno urbano gerado pelo modelo econômico social que privilegiou a cidade sobre o campo e que, em relação à cidade, descuidou-se da criação de equipamentos de políticas sociais e de geração de renda.

Com base em Vásquez (1990) e Minayo (1990), entre outros autores, percebe-se que a pobreza e a miséria podem ser situadas como conseqüências de uma violência produzida por um sistema social desigual. Neste sentido, o ambiente de pobreza passa a ser um cenário de violência, onde seus componentes atuam ora como vítimas, ora como autores dos processos conflitivos.

Especificamente sobre o processo saúde-doença, no artigo de Santos et al. (1990) há dados que revelam as doenças mais comuns as meninas envolvidas com a prostituição infantil em Fortaleza. Entre essas ressaltam-se as de pele; as sexualmente transmissíveis, principalmente a gonorréia e a sífilis; e, comumente entre as que dormem na rua, as infecções respiratórias, a exemplo da pneumonia e da bronquite. $\mathrm{O}$ artigo ressalta também que "nem todas as meninas têm condições de manter uma relação sexual completa, inclusive por falta de maturidade genital".

Ainda sobre este processo, em Dimenstein (1992) podem ser encontrados exemplos do cotidiano de meninas-protitutas da Amazônia legal. Entre as 53 entrevistadas, $15 \%$ usavam método contraceptivo, $5 \%$ utilizavam regularmente preservativo e $40 \%$ haviam feito aborto empregando métodos bem rudimentares, como chutes na barriga, drogas impróprias, a exemplo da quina (destinada à malária), e agulha de crochê. A maioria não possuía nenhum conhecimento sobre o funcionamento de seu corpo nem sobre os perigos da gravidez, e algumas meninas confundiam AIDS com cólera.

\section{CONSIDERAÇÕES FINAIS: PRINCÍPIOS PARA A SAÚDE PÚBLICA}

Diante do quadro onde se configura a prostituição infantil, fica patente, a existência, mais do que a necessidade, de uma demanda de Saúde Pública. Fica patente também que a demanda não se restringe a essa área. A partir desta perspectiva, percebe-se a necessidade de a saúde se articular a outros setores para que possa dar conta dessa realidade, dentro de uma perspectiva interdisciplinar.

Se, de um lado, é verdade que a temática em questão afigura-se como uma demanda de Saúde Pública, de outro também é verdade que praticamente não se tem investigado sobre ela. Apesar de existirem inúmeros artigos e alguns livros sobre o assunto, a ausência de pesquisas 
é sentida também em outros setores. O problema também já é reconhecido pela sociedade como tal, a ponto de ter sido instaurada, no corrente ano, uma Comissão Parlamentar de Inquérito (CPI) para investigar este assunto. No entanto, ainda faltam ser respondidas inúmeras questões sobre o problema, implicando a necessidade de se promover mais estudos.

Junto à existência de poucos trabalhos que tratam do problema aqui focalizado, há uma urgente necessidade de se desenvolverem ações sociais comprometidas com a mudança deste quadro. Neste sentido, afigura-se como importante a análise de programas que já vêm sendo desenvolvidos junto a meninas que vivem na rua. Algumas instituições vêm promovendo ações que contemplam a questão da prostituição infantil. Compreender como essas instituições vêm encaminhando o problema e que avanços vêm sendo conseguidos pode servir de ponto de partida para pesquisas no setor.

Nessas pesquisas pode-se entender o processo saúde-doença relacionado à prostituição infantil, articulando-se aspectos de extensão e a dimensão qualitativa do problema. Isso significa que junto à freqüência, à proporção e à correlação dos fatos, ressaltam-se como importantes, entre outros aspectos, os significados e a dinâmica da prostituição infantil, dentro do quadro das representações sociais.

Em termos de abordagem da problemática, assim como Minayo et al. (1992) observam que o olhar para o fenômeno dos "meninos e meninas de rua" deve ocorrer via família, também em relação à temática em questão o mesmo pode ser observado. Facilmente constata-se que, dentro de um quadro de miséria de famílias, crianças lançam-se à prostituição como forma de amenizar a fome e o frio, ou como forma de sair um pouco das ruas. Também constata-se que, dentro desse mesmo quadro de miséria, alguns pais vendem seus próprios filhos como "mercadoria", em troca de meios para o sustento da família. Estas constatações reforçam a necessidade de se abordar o problema a partir do universo familiar e articulá-lo às questões sociais mais fundamentais, introduzindo-se aí a atuação da Saúde Pública.

\section{RESUMO}

GOMES, R. Prostituição Infantil: Uma Questão de Saúde Pública. Cad. Saúde Públ., Rio de Janeiro, 10(1): 58-66, jan/mar, 1994.

Este artigo tem como objetivo analisar a prostituição infantil, a partir de uma revisão bibliográfica, com vistas a subsidiar a abordagem desta problemática no campo da Saúde Pública. Inicialmente, as categorias saúde, prostituição e violência são discutidas. Tradicionalmente, a prostituição em geral tem sido contemplada pelo saber médico, principalmente dentro de uma ótica higienista. Entretanto, a questão aqui colocada é de natureza distinta daquela presente nesse tradicional saber. Após essa discussão, são apontados aspectos sobre a dinâmica da cruel realidade brasileira, que revela o fato de crianças e adolescentes se prostituírem para sobreviver. Neste quadro, a prostituição infantil e a miséria entrecruzam-se, sem que a primeira se reduza à segunda. Ao longo da análise, procura-se estabelecer uma articulação entre diferentes obras sobre o assunto, no sentido de se contribuir para um avanço no campo do conhecimento relacionado à temática em questão. Finalmente, constata-se que, para se enfrentar o problema, faz-se necessário situá-lo dentro do contexto familiar e articulá-lo a questões macrossociais.

Palavras-Chave: Prostituição; Maus-Tratos Sexuais Infantis; Violência;

Saúde Pública

\section{REFERÊNCIAS BIBLIOGRÁFICAS}

AGUDELO, S. F., 1989. Violência y/o salud: elementos preliminares para pensarlas y actuar. I Encontro sobre Violência e Saúde, Rio de Janeiro: Claves/Ensp/Fiocruz. (Mimeo.)

AZEVEDO, M. A., 1986. Prostituição infantil: Uma incursão indignada pelo lado não-respeitável da sociedade. In: Quando a Criança Não Tem Vez: Violência e Desamor (M.H.F. Steiner, org.), pp. 109-113, São Paulo: Pioneira. (Série Cadernos de Educação)

BARRY, K., 1991. Prostitución y victimización. La mujer ausente: derechos humanos en el mundo Ediciones de las Mujeres, 15: 63-78. 
BIRMAN, J., 1991. Apresentação: interpretação e representação na saúde coletiva. Physis, 1: 07-22.

CARRARA, S., (s/d). A AIDS e a história das doenças venéreas no Brasil (de finais do século XIX até os anos vinte). Rio de Janeiro: Instituto de Medicina Social, Universidade Estadual do Rio de Janeiro. (Mimeo)

CEAP (Centro de Articulação de Populações Marginalizadas), 1993. A menina sai à rua. Revista CEAP, 3: 07-11.

DIMENSTEIN, G., 1992. Meninas da Noite: A Prostituição de Meninas Escravas no Brasil. São Paulo: Ática.

ENGEL, M. G., 1986. O médico, a prostituta e os significados do corpo In: História e Sexualidade no Brasil (R. Vainfas, org.), pp. 169-190, Rio de Janeiro: Graal.

, 1989. Meretrizes e Doutores: Saber Médico e Prostituição no Rio de Faneiro (18401890). São Paulo: Brasiliense.

GOLDENBERG, P.; MEDRADO, M. A. \& PASTERNOSTRO, M. A. N., 1989. A violência contra a mulher: Uma questão de saúde. In: $M u$ lher, Saúde e Sociedade no Brasil (M. E. Labra, org.), pp. 185-200, Petrópolis: Vozes.

FRENK, J., 1992. La nueva salud pública. In: La Crisis de la Salud Pública: Reflexiones para el Debate (Organización Panamericana de la Salud, org.), pp. 75-93, Washington, DC: OPAS. (Publicación Científica, 540)

GOFFMAN, E., 1988. Estigma: Notas sobre a Manipulação da Identidade Deteriorada. Rio de Janeiro: Guanabara.

LAMARÃO, M. L. N.; OLIVEIRA, M. B. S. \& MARIN, R. E. A., 1990. Cotidiano de Miséria e Formas de Exploração Sexual de meninas em Belém. Belém: Movimento República do Pequeno Vendedor - Centro de Defesa do Menor. (Mimeo)

LORENZI, M., 1987. Prostituição Infantil no Brasil e Outras Infâmias. Porto Alegre: Tché.

LUPPI, C. A., 1987. Malditos Frutos do Nosso Ventre. São Paulo: Ícone.

MACHADO, R.; LOURENO, A. L. R. \& MURICY, K., 1978. Danação da Norma. Medicina Social e Constituição da Psiquiatria no Brasil. Rio de Janeiro: Graal.

MINAYO, M. C. S., 1990. A violência na adolescência: um problema de saúde pública. Cadernos de Saúde Pública, 1: 278-291. , 1991. Abordagem antropológica para avaliação de políticas sociais. Revista de Saúde Pública, 25: 233-238.
, 1992. Violência e saúde. In: Pesquisa Social em Saúde (A. W. P. Spínola, E. N. C. Sá, M. F. Wsetphal, R. C. F. Adorno \& F. Zioni, coords.), pp. 257-267, São Paulo: Cortez.

MINAYO, M. C. S.;GOMES, R. CRUZ-NETO, O.; SOUZA, E. R.; ASSIS, S. G. \& PRADO, A. A., 1992. O ventre perverso da mãe rua. In: Saúde, Ambiente e Desenvolvimento (M. C. Leal, P. C. Sabroza, R. H. Rodriguez \& P. M. Buss, orgs.), vol. 2, pp. 279-294, São Paulo: Hucitec/Rio de Janeiro: Abrasco.

NUNES, E. D., 1988. A medida social no Brasil: um estudo de sua trajetória. Revista de Saúde Coletiva, 5: 97-111.

RUFFINO-NETTO, A., 1992. Qualidade de vida: compromisso histórico da epidemiologia. Saúde em Debate, 35: 63-67.

SAFFIOTI, H., 1989. Exploração sexual de crianças In: Crianças Vitimizadas: A Síndrome do Pequeno Poder (M. A. Azevedo \& V. N. A. Guerra, orgs.), pp. 49-95, São Paulo: Iglu.

SANTOS, C. M. A.; RODRIGUES, J. V.; QUEIROZ, M. O. \& PINHEIRO, A. A. A., 1990. Prostituição infantil: considerações teóricas e observações sobre a realidade da cidade de Fortaleza. Revista de Psicologia, 7/8: 97-113.

SANTOS, H.O., 1991. Crianças Violadas. Brasília: CBIA/CRAMI.

SCAMBLER, G.; PESWANI, R.; RENTON, A. \& SCAMBLER, A., 1990. Women prostitutes in the AIDS era. Sociology of Health $\mathcal{E}$ Illness, 12: 260-273.

SOARES, L. C., 1986. Da necessidade do bordel higienizado: tentativas de controle da prostituição carioca no século XIX. In: História e Sexualidade no Brasil (R. Vainfas, org.), pp. 143-168, Rio de Janeiro: Graal.

VASCONCELOS, A., 1991. A prostituição de meninas e adolescentes no Recife. Tempo e Presença, 258: 22-23.

VAZQUEZ, A. S., 1990. Filosofia da Práxis. Rio de Janeiro: Paze Terra.

VETHENCOURT, J. L., 1990. Psicologia de la violencia. Gaceta/APUCV, 62: 05-10.

VITIELO, N., 1989. Vitimização sexual: Conseqüências orgânicas. In: Crianças Vitimizadas: $A$ Síndrome do Pequeno Poder (M. A. Azevedo \& V. N. A. Guerra, orgs.), pp. 123-141, São Paulo: Iglu.

XAVIER, D.; ÁVILA, M. B. \& CORREA, S., 1989. Questões feministas para a ordem médica: O feminismo e o conceito de saúde integral. In: Mulher, Saúde e Sociedade no Brasil (M. E. Labra, org.), pp. 203-222, Petrópolis: Vozes. 